\title{
Analysis of On-line Survey about Need for Presence of Higher Education Institutions on Social Networks: a Step towards Creation of Communication Strategy
}

\author{
Kruno Golubić ${ }^{1}$ and Jadranka Lasić-Lazić ${ }^{2}$ \\ ${ }^{1}$ University Computing Centre (Srce), University of Zagreb, Croatia \\ ${ }^{2}$ Faculty of Humanities and Social Sciences, University of Zagreb, Croatia
}

\begin{abstract}
The use of social networks among higher education institutions in Croatia is not widespread. An anonymous on-line survey about the importance of institutional presence on social networks was conducted during a ten-day period in May 2011 and included a questionnaire which was distributed to students and employees of two Zagreb based institutions. The results of the survey are interpreted and presented in this paper. These results can be used as a general guideline toward the creation of communication strategy for the presence of higher education institutions on web based social networks.
\end{abstract}

Keywords: survey, presence on social networks, higher education institutions, communication strategy

\section{Introduction}

The goal of the on-line survey was to gather opinions and feedbacks on the need for official presence of higher education institutions on web based social networks. The term "official presence" is used in this paper to mean those forms of presence on social networks which are maintained by institutions themselves or by contracted individuals, social media agencies etc. The terms "web based social networks" and "social networks" are used to describe web sites, such as Facebook, LinkedIn and Twitter, whose purpose is gathering, communication and exchange of information and different contents (files, photos, video and audio records) within a closed group of users or with interested parties on the Internet. The use of social networks among higher education institutions in Croatia is currently not widespread. Previous research shows that only 18.8 percent of higher education institutions have some kind of official presence either on Facebook, LinkedIn or Twitter [2]. This is a rather low percentage, taking into consideration numerous possible usages [8] which could be beneficial to those institutions in their everyday activities [3] or emergency situations [4]. Although the methodology used for the afore mentioned research does not allow direct comparison with other similar researches [5], they nevertheless show a rather high acceptance level of social networks among some educational institutions, in some cases up to 100 percent. [1] Another great challenge is posed by constant emergence of new social networks [7] which means that institutions should know what potential audience they should reach (students, academic and non-academic staff and fund providers) and which social networks are best for them to use. On-line reputation can also pose a challenge for higher education institutions. [6]

\section{Research}

An anonymous on-line survey, conducted during a ten-day period in May 2011, included a questionnaire which was distributed to students and employees of two Zagreb based institutions 
- the Faculty of Humanities and Social Sciences (from here on it will be referred to as FHSS) and employees of the University Computing Centre. The e-mail sent to the employees of the University Computing Centre stated that the survey was primarily intended for those who currently had the status of student at any higher education institution. Attempting to create a snowball effect, the author stated in the survey invitation letter that it was allowed to forward the survey to other individuals affiliated in a certain way with an institution of higher education. The action of forwarding resulted in the data obtained from 18 other institutions four of which are not located in Croatia. The questionnaire consisted of seven questions and one field for contact information in case participants required a feedback from the survey conductor. The survey web page was opened 320 times, but 16 questionnaires were sent back empty so the data analysis was conducted on 304 survey sheets that were correctly filled out and sent back. Since none of the questions in the questionnaire were obligatory, the number of answers differed from one question to another.

\section{Findings and Interpretations}

The first question was "What is your affiliation with institutions of higher education?" This was a single choice question about the respondents' affiliation with institutions of higher education. Most of the responses came from undergraduate and graduate students. Second largest group was teaching and research staff. Table 1 shows a detailed distribution of participants based on their affiliation with higher education institutions.

\begin{tabular}{|l||c|c|}
\hline Answer & Response & $\%$ \\
\hline \hline $\begin{array}{l}\text { Undergraduate and } \\
\text { graduate student }\end{array}$ & 237 & 78 \\
\hline Post-graduate student & 18 & 6 \\
\hline $\begin{array}{l}\text { Non-teaching staff } \\
\text { (administration, maintenance, IT, ...) }\end{array}$ & 6 & 2 \\
\hline Teaching and research staff & 42 & 14 \\
\hline $\begin{array}{l}\text { No affiliation with } \\
\text { institutions of higher education }\end{array}$ & 1 & 0 \\
\hline TOTAL & 304 & 100 \\
\hline
\end{tabular}

Table 1. Distribution of participants.
Second question was "With which institutions of higher education are you affiliated?" Distribution of answers to this question is shown in Figure 1. Most of the survey participants, altogether 265, have stated that they are affiliated with the FHSS. Five out of 265 participants have entered additional institution into this field next to FHSS. From institutions other than FHSS, 22 participants completed this survey. Out of those 22 participants, 4 have stated they are affiliated with some institutions outside of Croatia. The third largest group is formed of 17 participants who have left this question unanswered. As it can be seen, intention of the authors to cause snow ball effect was not realized to the fullest possible extent since most of the participants belong to one institution.

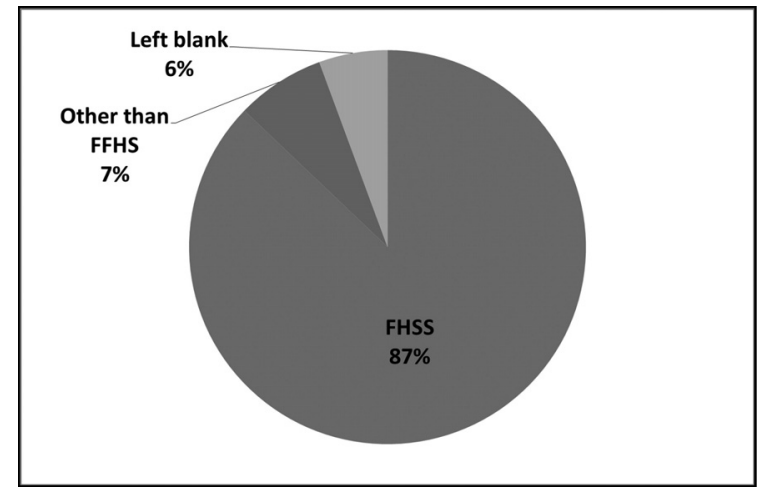

Figure 1. Institution affiliation.

In the next question participants could mark multiple answers as their response to the question "Mark the social networks that you use". The answers are given in Table 3. According to the earlier research [2] which indicated that Facebook, Linkedin and Twitter belong to the most popular social networks, these three networks were therefore offered in this survey as possible answers. With $76 \%$ of the answers, Facebook was marked as the most popular network among the survey participants. $20 \%$ of the participants do not use social networks. Facebook is the only social network used by 162 participants. Twitter or Linkedin were chosen only by three participants. Six participants have stated that they use exclusively some other social network. 


\begin{tabular}{|l||c|}
\hline Answer & Response \\
\hline \hline Facebook & 229 \\
\hline LinkedIn & 37 \\
\hline Twitter & 32 \\
\hline Some other social network & 37 \\
\hline I do not use social networks & 61 \\
\hline
\end{tabular}

Table 3. Usage of social networks.

The results for the usage of multiple social networks show that such practice is not widespread. Since there was no option to enter number of social networks used by participants, it is impossible to tell how many different social networks participants actually use. If we presume that the answer "Some other social network" counts only for one network, the results would be as follows: 2 participants use four different social networks, 21 participants use three different social networks and 45 of them use two different social networks.

The following multiple choice question was "Mark the social networks which show the presence of the higher education institution with which you are affiliated". This question was related to the participants' awareness of the official presence of higher education institutions on social networks. Most of the participants, or, more precisely, $62 \%$, answered that they were not aware of the status of their institution on social networks. The results for this question are shown in Table 4. Such rather high number of participants that are not aware of the institutions' status could have resulted from the fact that most institutions these days have web sites which they use for dissemination of information and therefore participants have no need to search for information at social networks. This correlates to some extent with the results shown in Figure 2.

Web browsing habits of participants was examined through the question "Which pages do you visit more often?" The results are shown in Figure 2. It is interesting to note that, despite the popularity of social networks, the participants still visit web sites of their institutions more often than those of social networks.

The percentage of answers to the question "Should higher education institutions, in your opinion, be officially present on social networks?" are shown in Figure 3. This question

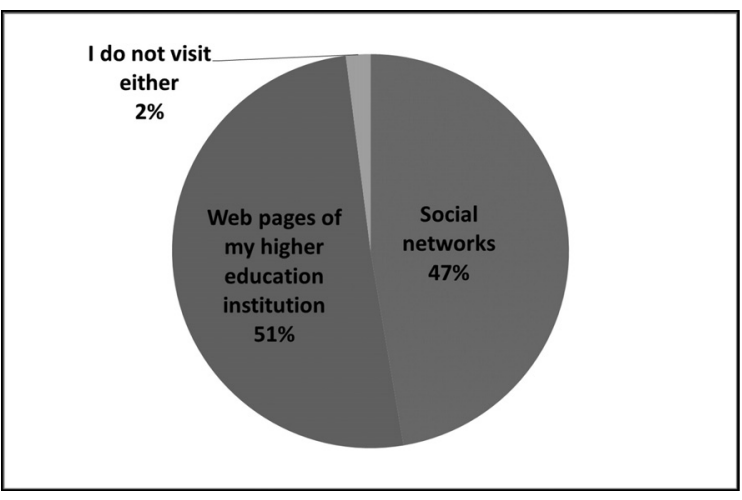

Figure 2. Web browsing habits.

\begin{tabular}{|l||c|}
\hline Answer & Response \\
\hline \hline Facebook & 58 \\
\hline LinkedIn & 6 \\
\hline Twitter & 2 \\
\hline Some other social network & 5 \\
\hline $\begin{array}{l}\text { Not officially present } \\
\text { on any social network }\end{array}$ & 62 \\
\hline I do not know & 187 \\
\hline $\begin{array}{l}\text { I have no affiliation with } \\
\text { institutions of higher education }\end{array}$ & 5 \\
\hline
\end{tabular}

Table 4. Presence of the institution.

leaves a lot of room for debate. Although the number of participants in favour of the presence on social networks is rather great, numerous participants are against it or they do not care about it. It remains to be seen what contributes to such a large number of participants having no opinion on this issue. One of the possible reasons could be the lack of information about possible usages of social networks by higher education institutions.

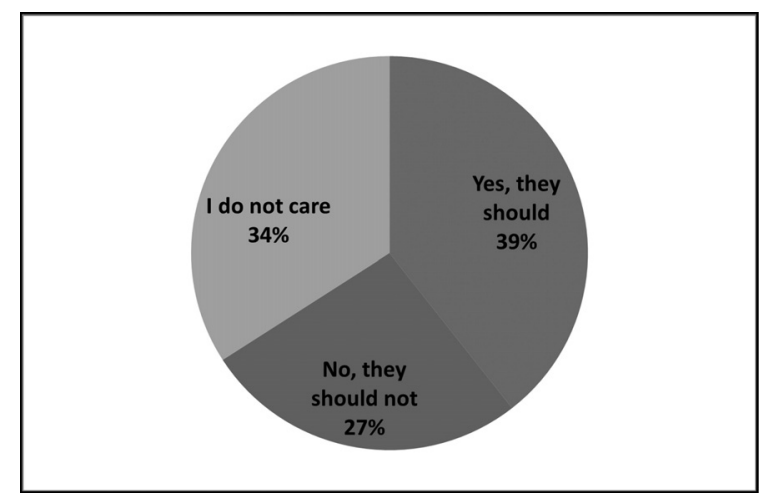

Figure 3. Participants' opinion about the need of institutional presence on social networks. 
The last question was a matrix of participants' opinions regarding several statements about social networks. Next three figures show distribution of the opinions for each statement that was offered.

Figure 4 presents participants' attitude toward the possibility of replacing current forms of web presence and communication with social networks. Despite the positive attitudes that participants have towards social networks, 224 of them do not think that social networks will replace regular web pages such as official web sites, blogs, etc. This clearly shows the opinion that other types of web pages will continue to coexist with social networks in years to come. The same is true for other forms of communication on the Internet. As many as 187 participants think that social networks will not replace existing forms of communication.

According to the participants' opinions shown in Figure 5, social networks are not considered as mere tools of entertainment and fun. This means that professional institutions, such

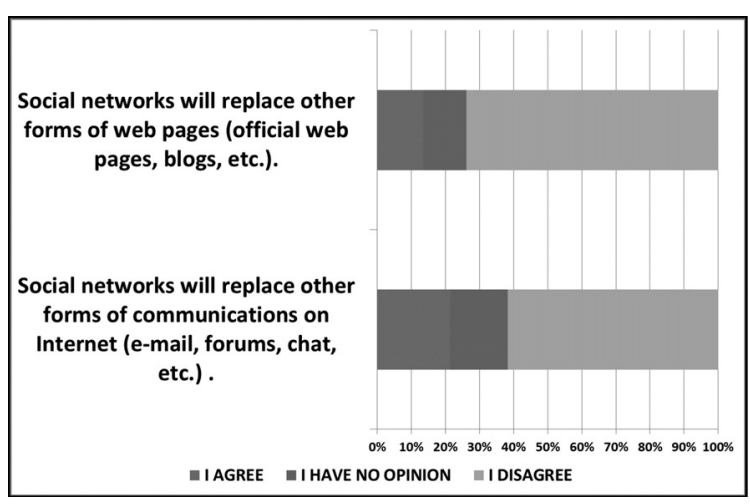

Figure 4. Comparison between social networks and traditional Internet services.

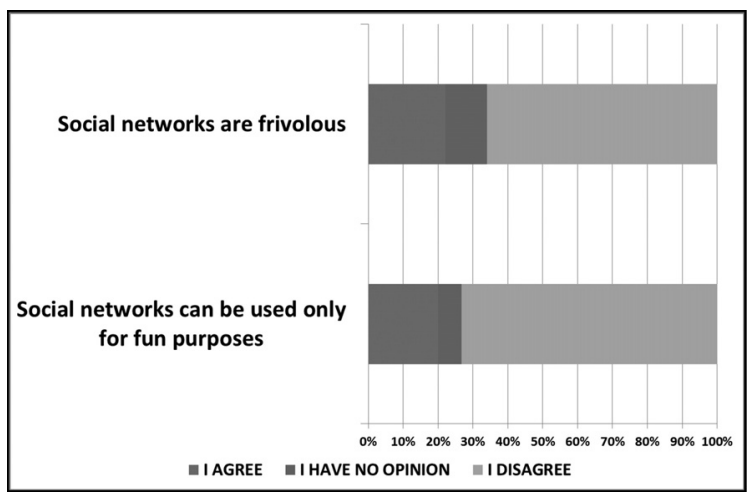

Figure 5. Perception of social networks. as academic ones, can use them without fear of being marked as "unprofessional and not serious".

Figure 6 shows that the participants are well aware of some characteristics of social networks, such as ease of use and quick dissemination of information. These two characteristics are very important for higher education institutions. Ease of use means that institutional users, i.e. the staff, can learn it easily and adopt it quickly. The speed of information dissemination can be of great use in cases of unplanned events, such as emergencies (e.g. natural disasters, power failure, etc.), or as a tool for last minute notice, e.g. cancellation of an exam or lecture.

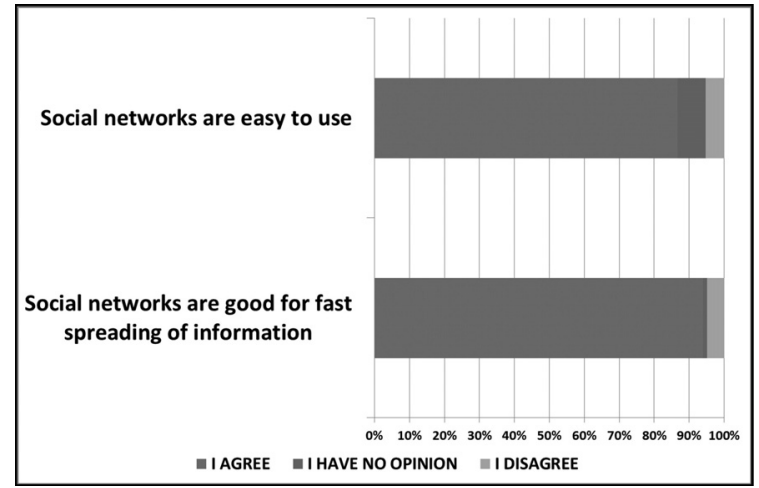

Figure 6. Characteristics of social networks.

Data shows that there is a slight difference between participants' responses to the questions that are very similar (Figures 3 and 7). Comparison of participants' opinions on these two statements is shown in Table 5. It remains unclear why participants changed their opinions.

Both data sets show the same thing, that there is no consensus on whether institutions should be officially present on social networks or not. This result was rather surprising.

The authors believe that the reason for a large number of indecisive participants lies in the currently low acceptance level of social networks among academic institutions in Croatia. Due to the low acceptance level, neither positive nor negative sides of the presence on social networks were visible to participants and therefore they did not form their own opinion on this issue. 


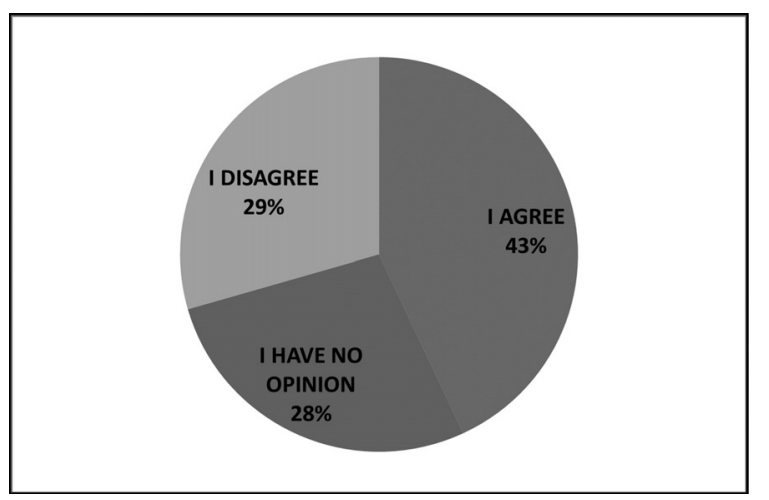

Figure 7. Responses to the statement "Higher education institution should be officially present on social networks".

\begin{tabular}{|l|c||l|c|}
\hline $\begin{array}{c}\text { Should higher education } \\
\text { institutions, in your opinion, } \\
\text { be officially present } \\
\text { on social networks? }\end{array}$ & $\begin{array}{c}\text { Higher education } \\
\text { institution should be } \\
\text { officially present on } \\
\text { social networks }\end{array}$ \\
\hline \hline Yes, they should & 119 & I agree & 130 \\
\hline No, they should not & 80 & I disagree & 89 \\
\hline I do not care & 103 & I have no opinion & 83 \\
\hline
\end{tabular}

Table 5. Comparison of questions.

\section{Conclusion}

The results of the survey show that people are aware of the good sides of social networks, but there is no consensus on whether institutions should be officially present on social networks or not. Data gathered from the participants in this survey can be used later on as a basis for the creation of a communication strategy on social networks. Such strategy can be vital if institutions decide to embrace social networks as a mode of communication. It is important for institutions to accept the fact that the world of social networks is constantly changing and that, once created, communication strategy will have to be revised as new technologies develop and new trends emerge. Before undertaking any steps for presence on social networks, each institution should identify the key issues that ought to be addressed in this process. A selection of social networks on which institutional presence would be created should be based on the type of content that will be presented and also on the preferences of possible users. A survey similar to this one can be undertaken to examine opinions of these potential users. Additionally, it is advisable to undertake certain actions before conducting a survey, such as information campaigns or distribution of communication strategy that would explain in more detail the desired goals of the presence on social networks. This could lead to a smaller number of indecisive participants, which would in the end produce much clearer picture of their preferences, even if it means that the time for the presence on social networks has not come yet.

\section{References}

[1] N. Barnes, A. Lescault, Social Media Adoption Soars as Higher-Ed Experiments and Reevaluates Its Use of New Communications Tools: 2011. http://bit.ly/Hzanny [2/7/2012]

[2] K. Golubić, The official presence of Croatian higher education institutions on social networks. In The future of information sciences : INFuture2011 - Information sciences and e-society (C. BILLENNESS, [ET AL.], EDITORS), (2011 Nov 9-11) pp. 263-275. Zagreb, Croatia. Zagreb: Department of Information Sciences, Faculty of Humanities and Social Sciences University of Zagreb, 2011.

[3] S. Kessler, 7 Ways Universities Are Using Facebook as a Marketing Tool. 2011. http://on.mash.to/HA28r4 [2/7/2012]

[4] S. LEWIS S, R u ok?: increasing perceptions of safety and community through social networks. In Proceedings of the $16^{\text {th }}$ ACM international conference on Supporting group work (W. LUTTERS, D. SONNENWALD, CHAIRS), (2010 Nov 7-10) pp. 319-320. Sanibel, USA, ACM.

[5] M. MATEŠIĆ, K. VučKović, Z. DOVEVAN, Social Software: Teaching Tool or Not? In INFuture 2009: digital resources and knowledge sharing (H. STANČIĆ, [ET AL.], EDITORS.), (2009 Nov 4-6) pp. 443-442. Zagreb, Croatia. Zagreb: Department of Information Sciences, Faculty of Humanities and Social Sciences University of Zagreb, 2011.

[6] M. MATEŠIĆ, K. VuČKović, Z. Dovevan, Should academia care about online reputation management and monitoring?. In Proceedings of the $33^{\text {rd }}$ International Convention (M. ČIČIN-ŠAIN, [ET AL.], EDITORS), (2010 May 24-28) pp. 852-857. MIPRO, 2010, Opatija, Croatia. Rijeka: Croatian Society for Information and Communication Technology, Electronics and Microelectronics.

[7] S. SMith, Pinterest Drives More Referrals Than Google+: 2012.

http://bit.ly/HyVltz [2/7/2012] 
[8] L. WANKEL, C. WANKEL, EDITORS, Higher Education Administration with Social Media: Including Applications in Student Affairs, Enrollment Management, Alumni Relations, and Career Centers. Bingley, Emerald Group Publishing, 2011.

Received: June, 2012 Accepted: August, 2012

Contact addresses:

Kruno Golubić University Computing Centre (Srce)

University of Zagreb

Marohnićeva 5

10000 Zagreb

Croatia

e-mail: kruno.golubic@srce.hr

Jadranka Lasić-Lazić Faculty of Humanities and Social Sciences University of Zagreb

Ivana Lučića 3

10000 Zagreb

Croatia

e-mail: jlazic@ffzg.hr
KRUNO GOLUBIĆ obtained his BE degree in IT Technologies in 2002, from the Polytechnic of Zagreb. In 2007 he obtained an MA degree in Information Science and Librarianship from the Faculty of Humanities and Social Sciences, University of Zagreb. He is currently a PhD student of Postgraduate Studies in Information and Communication Sciences at the Faculty of Humanities and Social Sciences, University of Zagreb. His primary role as an IT specialist at the Training and User Support Department of the University Computing Centre (SRCE), University of Zagreb is community management and presence of SRCE in social networks. He is a member of the Association for Computing Machinery (ACM).

JADRANKA LASIĆ-LAZIĆ, Ph.D. is a Full Professor of Information Science and the Head of the Postgraduate studies at the Department of Information and Communication Sciences, University of Zagreb, Croatia. She has a long experience in teaching on undergraduate, graduate and postgraduate levels. In her research she has run several national and international scientific projects and has published her work in books and scientific articles both on national and international levels. Her special interest is in research on e-learning, school libraries, information professionals education and knowledge organization. 